\title{
Mulemba
}

Revista Angolana de Ciências Sociais

4 (8) | 2014

Globalização, gestão e dinâmicas de desenvolvimento regional e local

\section{Para uma leitura de Sair da grande noite. Ensaio sobre a África descolonizada de Achille Mbembe}

\section{Virgílio Coelho}

\section{(2) OpenEdition \\ Journals}

Edição electrónica

URL: http://journals.openedition.org/mulemba/312

DOI: $10.4000 /$ mulemba.312

ISSN: 2520-0305

\section{Editora}

Edições Pedago

\section{Edição impressa}

Data de publição: 1 novembro 2014

Paginação: 619-631

ISSN: 2182-6471

\section{Refêrencia eletrónica}

Virgílio Coelho, «Para uma leitura de Sair da grande noite. Ensaio sobre a África descolonizada de Achille Mbembe», Mulemba [Online], 4 (8) | 2014, posto online no dia 20 novembro 2016, consultado o 27 janeiro 2021. URL: http://journals.openedition.org/mulemba/312 ; DOI: https://doi.org/10.4000/ mulemba.312

Este documento foi criado de forma automática no dia 27 janeiro 2021.

Tous droits réservés 


\title{
Para uma leitura de Sair da grande noite. Ensaio sobre a África descolonizada de Achille Mbembe
}

\author{
Virgílio Coelho
}

\section{NOTA DO AUTOR}

Texto da apresentação pública da obra do historiador e politólogo camaronês Achille MBEMBE, Sair da grande noite. Ensaio sobre a África descolonizada (Tradução de «Narrativa Traçada»; revisão de Sílvia Neto. Luanda, Edições Mulemba; Mangualde, Edições Pedago, 2014, 200p. [«Reler África»]), lido por ocasião das «Actividades alusivas à abertura do II semestre do ano lectivo 2014», no anfiteatro da Faculdade de Ciências Sociais (FCS) da Universidade Agostinho Neto (UAN), em Luanda, no dia 20 de Agosto de 2014.

1 Coube-nos, nesta cerimónia de «Actividades alusivas à abertura do II semestre do ano lectivo de 2014», a apresentação da obra Sair da grande noite. Ensaio sobre a África descolonizada, do politólogo e historiador de origem camaronesa Achille Mbembe. Não vamos ater-nos aqui ao seu interessante e vasto currículo de professor, investigador e de prolífero autor, pois, numa outra ocasião, o mesmo já foi aqui convocado aquando da apresentação da primeira das suas obras, que traduzimos para esta mesma colecção, intitulada África insubmissa. Cristianismo, poder e Estado na sociedade pós-colonial, um exercício que esteve a cargo do nosso colega «mais velho», Lucas Mbenghy Ngonda. ${ }^{1}$

Não falar do autor não implica que nos esquivemos de falar dele, mas antes de mais nada, começarei por reportar um facto curioso; sendo oriundo dos Camarões como já aludimos, a colecção «Reler África» rende uma justa homenagem a este país africano, que tem dado ao nosso continente e ao mundo intelectuais da mais alta estirpe, bem preparados e engajados pela causa do seu país e do nosso continente, como o são, por exemplo, o autor cuja obra ora apresentamos, conjuntamente com Axelle $\mathrm{Kabou}^{2} \mathrm{e}$ 
Jean-Marc Ela ${ }^{3}$, cujos trabalhos constituem algumas das principais obras já traduzidas e publicadas nessa colecção e que, ao que sabemos, têm sido muito procuradas tanto aqui no nosso país quanto em Portugal e no Brasil.

3 Achille Mbembe é um professor e investigador consagrado e a sua ampla e bastante difundida bibliografia ${ }^{4}$ atesta as suas qualidades de docente e investigador, no triângulo que traçou para operar: Europa (França), África (África do Sul) e Estados Unidos da América (USA), por onde se tem distribuído ao longo do ano, dando aulas (Vitwatersrand University e Duke University), fazendo investigação (WISER Vitwatersrand Institute for Social and Economic Research) e publicando, sobretudo em francês (França), mas também em inglês (USA). Foi professor de história na Columbia University (New York, USA) e na Pennsylvania University (Filadélfia, USA) e antes de se radicar na África do Sul, viveu em Dakar, Senegal, onde foi Secretário Executivo do CODESRIA - Conselho para o Desenvolvimento da Investigação em Ciências Sociais em África.

4 Na verdade, não se nos afigura que Paris, e de uma maneira geral a França, seja para Achille Mbembe a cidade-menina e país de olhos bonitos, pois, tal como ele próprio deixa entender, «[...] Antes de chegar a França, já tinha consciência do seu lado negro. Não tinha [a] França desempenhado um papel eminente nessa questão do crânio do morto - e, por isso, de recusa da sepultura e do desterro das vítimas que tombaram durante as lutas pela independência e autodeterminação no meu país? Não foi a sua política africana suficientemente ilustrativa sobre o facto de que não basta "descolonizar"; é ainda necessário operar uma verdadeira auto-descolonização? Paradoxalmente, não será a sua tradição de universalismo abstracto contrária à sua fé no dogma republicano da igualdade universal? No concernente a França e Paris, considerei-me sempre um indivíduo de passagem, em trânsito, rumo a um alhures (um passageiro)» (p. 41).

5 Ainda assim, e não obstante o pensamento negativo que grassa no seu espírito, pelas lembranças que guarda tanto da infância quanto da adolescência («os momentos difíceis e atrozes do fim da colonização em tempo de destruir e de arrasar», cf. pp. 32-40), a sua estadia por Paris em tempo de «passagem» (reproduzindo uma expressão de sua mãe), teve o mérito de lhe grangear boas coisas, já que, escreve, «[...] certos modos de pensar, de raciocinar e de argumentar tornaram-se-me familiares. Do ponto de vista do espírito, acabei por transformar-me num habitante, num herdeiro pela habituação à língua, aos gostos e aos costumes do país, e pelo convívio com certos aspectos da cultura erudita. Tinha à minha disposição o acervo do saber e do pensamento humanos. Devorei-os de tal forma que, hoje em dia, me considero, com toda a franqueza, um sucessor legítimo desse património. Não afirmou Fanon que nós seremos os herdeiros do mundo, no seu todo?» (p. 41).

6 A obra que agora se apresenta ao público foi pela primeira vez publicada na língua francesa em 2010, pela editora La Découverte, que deu continuidade à famosa editora francesa François Maspero dos anos 1950-1970 e da qual mantém alguns dos seus principais títulos, nomeadamente as obras do falecido intelectual e autor oriundo da Martinica Frantz Fanon, para o qual, conjuntamente com Jean-Marc Ela (outro gigante desaparecido do mundo dos vivos), «dois pensadores do futuro ilimitado» (sic), cuja obra o autor dedica à memória de ambos (p. 7).

7 De que é que trata esta obra? De acordo com o seu subtítulo, ela pretende ser um «ensaio sobre a África descolonizada», ou dito de outro modo, «o objecto central deste livro é a vaga de descolonização africanas do século XX» (p. 13); no entanto, não é uma obra que 
pretende «recontar a história, nem de fazer sociologia - e ainda menos de estabelecer tipologia» (p. 13); «não se trata também de fazer o balanço das independências» (p. 13).

A obra está organizada em cinco capítulos e cada um deles pressupõe uma estruturação de ideias abertas de um modelo de pensamento muito próprio. Achile Mbembe é um intelectual profundo e senhor de uma reflexão extraordinariamente amadurecida e isso é possível de ser constatado ao longo dos referidos capítulos, que se apresentam não apenas densos mas sobretudo altamente documentados.

9 O capítulo 1, intitulado "A partir do crânio de um morto. Trajectórias de uma vida» (pp. 31-48), é o que autor considera como sendo «um registo deliberadamente narrativo $e$ autobiográfico» (p. 15) e constitui quanto a nós, conjuntamente com o capítulo V, pelas suas características e incidências, os mais importantes desta obra. Constata-se que o autor procura reflectir a partir do seu próprio itinerário de vida, documentando com requinte e alguma precisão as suas lembranças da infância e adolescência no sítio que o viu nascer, e a qual o coloca como um «viajante» em busca da razão: a memória transporta-o desde o país de origem, a partir de uma descrição que mais se assemelha a desenhos etnográficos ou quadros de um pintor de quotidianos marcantes, como que autênticos dados recolhidos de um sonho, em que o registo fundamental é o espaço privilegiado da infância, repleta de inúmeras marcas do passado; os abusos infrigidos ao «cemitério» local, a «escola da missão católica», a «[...] escuridão da noite - máscara opaca e, no entanto, tão penetrável - me imbuía, todas as vezes, de um medo indescritível com a sua legião de pirilampos sobre os quais se dizia repetidamente que, em cada um, germinava um fantasma, com os seus cânticos lúgubres de sabor enferrujado, salgados das corrupções da feitiçaria, essa espécie de lapidação, de exaurimento perverso e desmesurado, que resisitia aos destroços do dia e às eras do mundo, com o crânio das cavernas» (p. 33). Ele que não era devoto (p. 34), «Porém, o cruxifixo suscitou a minha curiosidade durante um largo período de tempo» (p. 34) e marcara bem na sua mente de criança as representações alusivas ao mês de Dezembro, com «o prenúncio do Natal, outra sequência do calendário cristão» (p. 33), «as lendas sibilantes do critianismo [...] as Páscoas, antecedidas, anualmente, pelo Domingo de Ramos e por vias-sacras infindáveis: a Quaresma, como é evidente a oração, a penitência, os cânticos monótonos de idosas proferindo o Stabat Mater a meio da tarde, as catorze estações, a cruxificação e a sepultura, Judas, Pilatos, o Gólgota e a Ressureição» (pp. 33-34). Tudo isso e mais alguma coisa preenchia a mente deste adolescente, que «Não sabia como lidar com o cristianismo até que, muito tempo depois, numa tarde, na biblioteca dos padres dominicanos, peguei quase por acaso num livro da autoria de um teólogo peruano, Gustavo Gutierrez, intitulado Théologie de la libération. $O$ autor ajudou-me repensar o cristianismo como memória e linguagem da insubmissão, como narrativa da libertação e ligação a um acontecimento, seja de ordem simbólica, hiperbólica, mítica ou histórica - a morte e a ressureição de um homem nascido em Belém e crucificado pelo poder público do Gólgota, após um calvário espinhoso. Ajudou-me também a concebê-lo como um relato crítico dos potentados e das autoridades, uma poética social, um sonho subversivo e uma recordação prosélita, a actuação de uma linguagem (literal e figurada) sobre o sentido da vida. Porém, fez-me ainda compreender que o além da morte merece ser pensado enquanto tal, como anterior a qualquer estância do mundo histórico» (p. 34).

Dessa observação e constatação, escreve em «fragmentos de memória» (pp. 32-35): «[...] Distingo os túmulos sob o anteparo das habitações, ou na beira da estrada, bem como nesse cemitério abandonado, no coração da aldeia, mesmo diante da concesso do chefe, entre as árvores e uma ou duas palmeiras denunciando o fardo do tempo, junto dos coqueiros e da capela, 
e onde, um dia o Caterpillar que levava a cabo as obras de reconstrução da estrada acabou por abrir uma sepultura, desordenando umas velhas ossadas, dispersando-as e arrastando-as pela vala, quais objectos perdidos, atirados à frente dos nossos olhos, como farrapos» (p. 32). Esta descrição, tal como tantas outras sentidas aqui como noutros lugares, mostra bem o quanto a colonização não respeitava nada, não respeitava as coisas mínimas que tornavam grandes as comunidades, nomeadamente o cemitério, o lugar dos mortos por excelência e por certo dos antepassados da comunidade, enfim, as marcas que entre os africanos estabelecem a ligação intrínseca entre vida e morte.

11 A sua escrita é fluente, melodiosa, mas ganha muitas vezes o tom sarcástico, como o desta passagem: «Nasci afortunadamente num dia de Julho, já o mês se aproximava do fim, numa região africana à qual foi atribuído, tardiamente, o nome de "Camarões", em homenagem à admiração que se apoderou dos navegadores portugueses do século XV quando, ao subirem o rio nas cercanias de Douala, se depararam com a presença de uma multidão de crustáceos e baptizaram o local de "Rio dos Camarões"» (p. 32). A constatação, permite-lhe concluir o que se segue: «[...] Cresci à sombra dessa região desprovida de nome próprio, pois, em certo sentido, o nome que [o país] ostenta é fruto do espanto de um outro» (p. 32), neste caso estrangeiros, navegadores portugueses (p. 32). E ainda: «Na cercadura de uma das várias florestas do sul, passei muito tempo à sombra de uma aldeia cujo nome não tem nome - muito tempo à sombra das suas histórias e da sua gente que ainda preservo a memória, assim como quem faleceu durante a minha adolescência ou pereceu posteriormente na minha ausência dada a minha partida, ainda sei os seus nomes e consigo ver os seus nomes. Ainda oiço o rufar dos tambores anunciando a passagem deste ou daquele deste mundo para o outro» (p. 32). E conclui: «Trata-se da palavra certa, "passagem", pois era essa que a minha mãe utilizava para evitar pronunciar a terrível Outra, a "morte". Tudo isso vivenciei nessa aldeia» (p. 32).

Escrito sob a linha de pensamento do filósofo alemão Martin Heidegger, no seu escrito «Pourquoi les poètes?», uma longa transcrição define a epígrafe ao capítulo, cuja intenção ou destino final é a compreensão do que se pressupõe uma viragem, apenas possível de ocorrer quando os mortais encontrarem a sua própria essência. Ora as recordações do autor navegam por «lutos e exéquias, das histórias que se contavam nessas ocasiões: sobre este ou aquele cuja sombra, num dia deslumbrante, foi avistada nos campos onde essa mesma pessoa costumava trabalhar» (p. 32). Algo semelhante ocorreu com o "outro que se ergueu das entranhas da terra para prosseguir com os passeios, cortar a madeira, extrair o vinho de palma, visitar a sua casa já caída a noite, refazendo assim o caminho sempre inconcluso que, desde tempos imemoriais, é suposto culminar na morte e vice-versa, numa espécie de epifania mágica que encandeava por completo o meu espírito de medo de medo e de êxtase» (p. 32). E as recordações percorrem assim parte do capítulo, preenchidas de factos e lembranças que posicionam o autor perante a sociedade colonial de antanho...

13 As lembranças acerca dos mortos sem cerimónias devidas nem sepulturas, quando a repressão colonial se agrava e o movimento de independência se vê encurralado numa luta desigual, sendo destroçados militarmente pelo exército da entidade colonial francesa, ao que se seguiu a execução dos dirigentes nacionalistas e, entre estes, o dirigente maquisard Ruben Um Nyobè ${ }^{5}$ um assassínio que lembra outros combatentes da luta pela independência, tais como Patrice Lumumba, Amílcar Cabral, Eduardo Mondlane e tantos outros mártires africanos pela independência (p. 35). O caso deste herói como de tantos outros, cujos corpos não foram jamais encontrados, mantém em suspenso na velha tradição africana, sobre a necessidade de serem efectuadas as cerimónias tendentes a um funeral e enterramento digno, o que leva muito justamente 
o autor a se interrogar acerca do crâneo do falecido, um facto que prefigura assim o título do capítulo (p. 36). Nem o afastamento desses lugares, nem muito menos o deambular que ainda hoje o mantém por terras estrangeiras lhe tolda o espírito e lhe faz esquecer a vivência da infância.

14 Já vimos o seu pensamento sobre Paris e sobre a França, no qual vivencia a vida como um passageiro e se vem a tornar mais tarde num habitante, num herdeiro e finalmente num sucessor legítimo de todo o património de saber herdado. Diferentemente, a longa estadia em New York permitiu-lhe entrar efectivamente nos Estados Unidos e graças à qual, «pela primeira vez começa a ter uma visão do mundo e fui, de súbito, ao seu encontro» (p. 42). Finalmente, a África no Sul, onde hoje passa parte de sua vida e trabalha, «[...] era também um país de múltiplos enclaves: o país da concatenação dos mundos, das nações e dos sistemas» (p. 43).

Em «Abertura do mundo e ascenção da humanidade», que configura o capítulo II desta obra (pp. 49-77), é um longo capítulo que procura dar respostas às múltiplas interrogações colocadas pelo autor, acerca do que se pretende efectivamente, já que, «a descolonização - contanto que um conceito tão aberto possa constituir uma marca - não terá passado de um fantasma sem densidade? Em última análise, não terá sido apenas um acidente tumultuoso, um estilhaço à superfície, uma pequena fenda externa, o sinal de um futuro a subtrair-se? Será a dualidade colonização/descolonização dotada de um único sentido? Enquanto fenómenos históricos, uma não se reflectirá na outra, uma não implicará a outra, como duas faces de um mesmo espelho?» (p. 14).

Sendo estas algumas das interrogações que esta obra procura analisar e dar respostas, o autor parte de múltiplos recursos e procura circunscrevê-los sob o escopo de múltiplos entendimentos acerca da descolonização, «[...] um acontecimento cujo significado político essencial residiu na vontade activa de comunidade [...] na vontade [de ascender] de poder. Essa vontade de comunidade era o outro nome daquilo que se poderia designar por vontade de viver. Visava a realização de uma obra partilhada: suster-se a si própria e construir uma herança» (p. 13). E conclui: «[...] Como uma seta [tais ideias] serviam para apontar para o futuro e impôr, pela práxis, uma nova redistribuição da linguagem e uma lógica do sentido e da vida» (pp. 13-14).

17 Assim, na sua forma ínfima, a descolonização «designa, simplesmente a tranferência de poder da Metrópole para as antigas colónias, aquando da independência» (p. 49). No entanto, baseado em múltipla bibliografia, Mbembe escreve que «essa transferência de poder é geralmente o fruto de negociações pacíficas e compromissos assumidos entre as elites políticas dos novos países independentes e as antigas potências coloniais, ou uma consequência de uma luta armada para abolir a ascendência estrangeira, resultando na derrota, ou mesmo na evicção dos colonos e na reapropriação do território nacional pelo novo poder autóctone» (p. 49).

$\mathrm{O}$ autor, baseado em factos históricos e munido de uma aparelhagem conceptual bem estruturada, argumenta longamente acerca da natureza e o carácter da descolonização em África, começando por a enquadrar como «uma plena categoria política, polêmica e cultural» (p. 49) assemelhando-se, por esse prisma, a uma «luta de libertação» ou a uma «revolução», nas palavras de Amílcar Cabral, intelectual e dirigente político do Partido Africano da Luta pela Independência da Guiné e Cabo Verde (PAIGC). Concluindo, «essa luta almejava a reconquista, por parte dos colonizados, da superfície, dos horizontes, das profundezas e das eminências da sua vida» (p. 49).

É seu entendimento, que a organização e o desenvolvimento da luta política revolucionária implicava além de considerável esforço físico e capacidades 
extraordinárias de mobilização das massas, a necessidade do desmantelamento completo das estruturas da colonização e a instituição de «novas relações entre o sujeito $e$ o mundo, reabilitando-se o possível» (p. 50). No entanto, Achille Mbembe entende que à «[...] luz de tal perspectiva, o conceito da descolonização revela-se elíptico, remetendo para a difícil problemática da reconstituição do sujeito, da abertura do mundo e da ascensão universal da humanidade, evocando as principais linhas do trajecto [...]» (p. 50). E porque não há uma teoria acerca da descolonização que propriamente responda às múltiplas interrogações colocadas, o autor serve-se da história hodierna da descolonização, considerando-a como «um dos momentos de transição daquilo que poderia designar-se por modernidade tardia», já que, «é ela que assinala a reapropriação planetária dos ideais da modernidade e da sua transnacionalização» (p. 53). Os recursos explicativos utilizados levam-nos desde os primórdios das independências em África e alhures («Haiti e a Libéria: duas falhas» (pp. 53-56), em seguida, o debate passa para as questões da «Raça e a descolonização do saber» (pp. 57-56), até ao «Nascimento de um pensamento mundo» (pp. 64-72), e conclui em «A dupla estrutura de incapacidade e de ignorância» (pp. 73-77). Essa longa démarche, essa busca incessante de respostas às múltiplas inquietações, transporta-nos segundo o autor para o centro de um novo debate, que retoma a "colonização» e aquilo que ele designa por «a sua pós-vida», uma vez que constitui «o cerne dos debates contemporâneos acerca da pós-colonialidade». No entender de Achille Mbembe, «a colonização criou uma nova estrutura de acção e de sentido, um novo regime de historicidade [...]. Esse processo de reordenação do campo no qual se desenrolam agora as interacções entre dominadores $e$ subjugados coloniais em nada atenua o conjunto dos costumes e das lógicas autóctones preexistentes» (pp. 73-74). É por isso que este capítulo se articula e complementa o capítulo V, «África: a casa sem chaves» (pp. 141-190), pois aqui são analisados os momentos históricos desde a implementação das fronteiras africanas anteriores à Conferência de Berlim (1884-1885), que se sucedem à abolição do tráfico de escravos até à submissão dos primeiros movimentos de resistência.

Os capítulos III e IV pelas matérias que tratam são complementares. O capítulo III, «Sociedade francesa: proximidade e reciprocidade» (pp. 79-99), ajuda-nos sobretudo a entender os posicionamentos actuais da França, que «teima em não pensar a pós-colónia de forma crítica», isto é, «a história da sua presença no mundo e a história da presença do mundo no seu seio tanto antes, quanto durante ou após o Império». Ao longo destas cerca de 20 páginas, de texto cerrado e repleto de questões sobre a problemática da raça no projecto colonial francês é posterior a descolonização, o que tende a prenunciar «o declínio de uma nação cristalizada» (pp. 81-89). Já o capítulo IV, «O longo inverno imperial francês» (pp. 101-139), longo nas suas 38 páginas repletas de um discurso extraordinariamente denso e bem documentado, analisa a situação da França sobre o seu posicionamento acerca das questões pós-coloniais. A base conceptual deste capítulo assenta no facto da negação por parte da França de introduzir para o debate as questões pós-coloniais, questões essas subsequentes à descolonização, no mesmo momento em que outros países como os Estados Unidos e a Grã-Bretanha, mas igualmente em outros recantos do mundo, como a América do Sul, a Austrália e Nova Zelândia, o subcontinente indiano, a África do Sul, o fizeram. Esse acto negativo por parte de um país colonizador se deve ao facto de ignorar o que nesses outros países já se estava a fazer, pois, «quando a corrente começa a ganhar ascendência nos meios académicos e artísticos anglo-saxónicos, a França política e cultural, avançando em sentido oposto, entra naquilo que se poderia designar por "inverno imperial"» (daí o título do capítulo). Sob a perspectiva da história intelectual, esse inverno caracteriza-se por uma série de «suspensões», 
anátemas e grandes ex-comunhões saldadas pela regressão relativa de um pensamento francês de cariz verdadeiramente planetário (p. 103).

21 Mas, na realidade, de que se trata quando falamos de estudos pós-coloniais?

22 Resumindo Achille Mbembe, podemos dizer que há cerca de 25 anos, mais ou menos na década de 1990, verificou-se uma «viragem pós-colonial nas ciências sociais e humanas» e desde essa data, «a crítica pós-colonial inspira inúmeros debates políticos, epistemológicos, institucionais e disciplinares» praticamente em todo o mundo desenvolvido. Em que consistem os fundamentos teóricos e conceptuais desses novos estudos?

A esse propósito Achille Mbembe nos esclarece:

«Desde a sua eclosão, esse pensamento foi objecto de interpretações muito diversas e suscitou, em intervalos relativamente frequentes, vagas polémicas e controversas - que aliás persistem - e mesmo contestações totalmente contraditórias entre si. Também engendrou práticas intelectuais, políticas e estéticas tão profusas quanto divergentes, a ponto de, por vezes, se questionar acerca dos elementos constitutivos da unidade. Não obstante essa fragmentação, pode afirmar-se que, no seu núcleo central, a crítica pós-colonial visa aquilo que poderia designar-se pela interpolação das histórias e a concatenação dos mundos. Dado que a escravatura, e sobretudo a colonização (mas também as migrações, a circulação das formas e dos imagionários, dos bens, das ideias e das pessoas) desempenhou um papel decisivo nesse processo de colisão e de imbricação dos povos, não é surpreendente que as tenha convertido nos objectos privilegiados dos seus estudos» (pp. 101-102).

Ademais, escreve ainda o autor,

«O sumo do pensamento pós-colonial não considera a colonização nem como uma estrutura imutável e anistórica, nem como uma entidade abstracta, mas como um processo complexo de invenção de fronteiras e intervalos, de zonas de passagem e espaços intersticiais ou de trânsito. Paralelamente, sustenta que, enquanto força histórica e moderna, uma das suas funções consistia na produção da subalternidade. Nos seus impérios, várias potências coloniais tinham instaurado uma subordinação assente em bases raciais e estatutos jurídicos por vezes diferenciados, mas sempre, e em última instância, inferiorizantes. Em contrapartida, com vista a articular as suas reivindicações à luz da igualdade, muitos sujeitos coloniais procederam à crítica dos erros que a lei da raça e araça da lei (e a do género e a da sexualidade) tinham contribuído para criar. Logo, o pensamento pós-colonial analisa o trabalho concretizado pela raça bem como as diferenças assentes no género e na sexualidade no imaginário colonial, as suas funções no processo de subjectivação dos subjugados coloniais. Paralelamente, debruça-se sobre a análise dos fenómenos de resistência que marcaram a história colonial, as diversas experiências de emancipação e os seus limites, tal como os povos oprimidos se constituíram sujeitos históricos e influenciaram muito caracteristicamente a constituição de um mundo transnacional e diaspórico. Por fim, incide sobre a forma como os vestígios do passado colonial são actualmente objecto de um trabalho simbólico e prático, bem como as condições segundo as quais esse trabalho produz formas inéditas, híbridas ou cosmopolitas, na via e na política, na cultura e na modernidade» (p. 102).

Eis aqui em resumo a lógica fundamental da obra de Achille Mbembe, Sair da grande noite. Ensaio sobre a África descolonizada, para a qual auguramos que tenha muitos leitores. 


\section{NOTAS}

1. Sobre o assunto cf. Achille Mbembe, África insubmissa. Cristianismo, poder e Estado na sociedade pós-colonial. Tradução de "Narrativa Traçada»; revisão Isabel Henriques e Pedro M. Patacho. Luanda, Edições Mulemba; Mangualde Edições Pedago, 2013, 168p. [«Reler África»]. A apresentação entre nós deveu-se ao sociólogo e Professor Associado da Faculdade de Economia da Universidade Agostinho Neto (UAN), Lucas Mbenghy Ngonda, «Algumas notas para uma leitura de "África insubmissa" do politólogo e historiador camaronês Achille Mbembe», Mulemba - Revista Angolana de Ciências Sociais (Luanda), vol. III, n. ํ 6, Novembro de 2013, pp. 349-354.

2. Cf. Axelle Kabou, E se a África recusasse o desenvolvimento? Tradução de Glória Sousa; revisão de Isabel Henriques e Pedro M. Patacho. Luanda, Edições Mulemba; Mangualde, Edições Pedago, 2013, 184p. [«Reler África»]; a apresentação entre nós coube ao economista e vice-Decano da Faculdade de Economia da Universidade Agostinho Neto (UAN), João C. Ferreira, «A atitude dos africanos face ao desenvolvimento. Notas a propósito da obra de Axelle Kabou: "E se a África recusasse o desenvolvimento" ", Mulemba - Revista Angolana de Ciências Sociais (Luanda), vol. III, n.․ 6, Novembro de 2013, pp. 341-348.

3. Cf. Jean-Marc Ela, Restituir a história às sociedades africanas. Promover as Ciências Sociais na África Negra. Tradução de Maria Teresa Moreira; revisão de Isabel Henriques e Pedro M. Patacho. Luanda, Edições Mulemba; Mangualde, Edições Pedago, 2013, 98p. [«Reler África»]. A apresentação entre nós foi efectuada pela antropóloga e chefe do Departamento de Antropologia da Faculdade de Ciências Sociais da Universidade Agostinho Neto (UAN), cf. Rosa Melo, «O imperativo apelo de Jean-Marc Ela: Restituir a história às sociedades africanas e promover as Ciências Sociais na África Negra», Mulemba - Revista Angolana de Ciências Sociais (Luanda), vol. IV, n. ${ }^{7}$, Maio de 2014, pp. 521-525.

4. Publicou, além de artigos em revistas especializadas e em capítulos de livros, as obras seguintes: Les jeunes et l'ordre politique en Afrique Noire (Paris, L'Harmattan, 1985); Afriques indociles. Christianisme, pouvoir et État en société postcoloniale (Paris, Karthala, 1988); La naissance du maquis dans le Sud-Cameroun (1920-1960). Histoire des usages de la raison en colonie (Paris, Karthala, 1996); De la postcolonie. Essai sur l'imagination politique dans l'Afrique contemporaine (Paris, Karthala [«Les Afriques»], 2000); Sortir de la grand nuit. Essai sur l'Afrique décolonisée (Paris, La Découverte ["Cahiers Libres»], 2010); Critique de la raison nègre (Paris, La Découverte [«Cahiers Libres»], 2013); Le politique par le bas en Afrique noire. Contributions a une problématique de la démocratie, com JeanFrançois Bayart e Comi Toulabor (Paris, Karthala, 1992); Johannesburg. The elusive metropolis, com Sarah Nuttall (Durham, Duke University Press, 2008); e Ruptures postcoloniales, com Nicolas Bancel, Florence Bernault, Pascal Blanchard, Ahmed Boubekar e Françoise Verger (Paris, La Découvert, 2010).

5. Cf. La naissance du maquis dans le Sud-Cameroun (1920-1960). Histoire des usages de la raison en colonie, op. cit. 


\section{AUTOR}

\section{VIRGÍLIO COELHO}

virgiliocoelho@hotmail.com

Professor Auxiliar do Departamento de Antropologia da Faculdade de Ciências Sociais (FCS) da Universidade Agostinho Neto (UAN), Director das Edições Mulemba e Editor da Mulemba - Revista Angolana de Ciências Sociais da FCS da UAN.

Professor Auxiliar do Departamento de Antropologia (DA) da Faculdade de Ciências Sociais (FCS) da Universidade Agostinho Neto (UAN), é antropológo, diplomado pela École Pratique des Hautes Études (EPHE), Universidade de Paris - Sorbonne (França), tendo apresentado a tese intitulada La place des jumeaux dans le système religieux des Ndongo (Ambundu), Angola (523p.), onde também efectuou estudos doutorais em Antropologia Social e Cultural, sob a direcção do Prof. Doutor Michel Cartry. Concluiu o mestrado: Diplôme d'études approfondis (DEA), na especialidade de «Anthropologie comparée des Religions d'Afrique, d'Orient et d'Extreme Orient», em 1988, sob a direcção da Prof. ․ Doutora Jacqueline Duvernay-Bolens, tendo submetido a tese Le culte des «génies» ítùtà chez les Ndongo de la valée du Kwanza, Angola (176p.). É investigador (Assessor Principal) do Ministério da Cultura, onde dirigiu algumas das suas instituições, dentre as quais o Departamento de Folclore da Direcção Nacional de Arte (DINARTE) e a Delegação Provincial de Luanda (DPL). De Janeiro de 2003 a Setembro de 2008, foi ViceMinistro da Cultura para o Património e a investigação científica, no âmbito do Governo de unidade e reconciliação nacional (GURN). No âmbito do ensino, é docente no curso de Antropologia do Departamento de Antropologia da Faculdade de Ciências Sociais (FCS) da Universidade Agostinho Neto (UAN), orientando formação nas cadeiras seguintes: Introdução à Antropologia; Etnologia Geral; Semiótica e Semiologia; Tradições Orais, Mitos e Mitologias; Antropologia das Religiões; Epistemologias Antropológicas e Teorias Antropológicas. Em 2010 foilhe outorgado o «Prémio Nacional de Cultura e Artes», na secção de Ciências Humanas e Sociais, pelas obras «Em busca de Kábàsà!...» Estudos e reflexões sobre o «Reino» do Ndòngò. Contribuições para a História de Angola e Os Túmúndòngò, os «génios» da natureza e o Kílàmbà. Estudos sobre a sociedade e a cultura kímbùndù. 